\title{
Premarital Romantic and Sexual Relationship among Unmarried Young Adults in India-An Overview
}

\author{
D. Barani Ganth* \\ *Department of Applied Psychology, Pondicherry University
}

\begin{abstract}
Family relationships in India are fast changing with the advent of globalization. While parents endorse arranged marriages for their wards, young Indians are increasingly interested in romantic autonomy and marriages of choice. The phenomenon of romantic relationship has been studied for long in the west though the attention on majority world has not been adequate. However, a handful of studies have examined premarital romantic and sexual relationship among Indian youth with the objective of understanding the correlates, predictors, and concomitants of romantic relationship in Indian context. A few cross-cultural studies were conducted comparing the romantic pursuits of Indian youth with the western youth, through the cultural lens. The present paper provides an overview of these studies and offer recommendations for effectively handling issues arising out of romantic relationship in Indian cultural context.
\end{abstract}

\section{INTRODUCTION}

India is a country with rich cultural diversity and traditional systems. Family relationships in Indian society have been historically entrenched within fixed social networks bound by kinship barriers (Dhariwal \& Connoly, 2013). Unlike Western societies wherein youth enjoy relational choice to form, develop and terminate peer and romantic relationships, youth in India are monitored and governed by parents in these domains (Gupta, 1976). However, with globalization and exposure to western media and virtual social networking with heterogeneous peer group, young adults in India are in transition in attaining romantic agency and autonomy. Though romantic relationship is a normative development within the cultural context, most research on this topic has been conducted in the Western world ignoring the Eastern cultures, especially the traditional ones such as India. However, recently, scholarly empirical research studies from India and a few cross-cultural studies from the west are reported in the literature. The focus of these studies are primarily examining the romantic and sexual experiences and its correlates among Indian youth. The objective of this paper is to present an overview of those studies. In the context of increasing family conflicts on the issues related to romantic relationships, a few recommendations to policy makers, parents and youth are also presented.

\section{Studies in Indian Context}

In order to empirically examine the correlates and predictors of premarital sexual relationship among Indian youth, Abraham and Kumar (1999) conducted a study on college students in Mumbai. Nine hundred and sixty-six low-income college students enrolled in Mumbai city were surveyed. Results showed that $47 \%$ of boys and $13 \%$ of girls had some form of premarital sexual experience. Amongst them $26 \%$ boys and $3 \%$ girls, respectively, had sexual intercourse. Age and personal income were two factors that had an effect on the sexual behaviour of students. Students' knowledge about sexuality-related issues, attitudes toward sex, and levels of social interaction and exposure to erotic materials emerged as stronger predictors. The authors opined that traditional norms and the role of the family are weakening in governing young people's sexual behavior in India. They also recommended school-based sexuality awareness programs to create awareness about pregnancy, contraception and sexually transmitted diseases. In another paper using Focus Group Discussions (FGD) and in-depth interviews, Abraham (2002) examined three typologies of heterosexual peer networks identified namely ' bhai-behen ' ('brother sister like'), romantic 'true love', and transitory and sexual 'time pass' relationships. The author emphasized that these "three typologies were the outcome of strong cultural norms of heterosexuality and they define the boundaries of sexual behaviour for unmarried youth". The analysis of the data revealed that the bhai-behen category distinguished the tabooed true love heterosexual relationship and time pass friendships from a more socially acceptable brother sister like relationships. It was also found that boys took advantage of the fluidity in the categorization as they wished to engage in multiple relationships, while girls mainly engaged in single, true love relationships. These findings paint a view of premarital relationship culture among college youth in metropolitan India.

In a qualitative design, Alexander, Garda, Kanade, Jejeebhoy and Ganatra (2006) examined premarital partnership among youth in rural and an urban slum setting in Pune district, India. Analysis of the data showed that $25-40 \%$ of young men and $14-17 \%$ of young women reported opposite-sex friends. Youth had such friends 
from their neighborhood using different strategies. Boys and girls differed with regard to their initiations in romantic relationship, proposal and partners. They also differed in terms of physical intimacy such as handholding, kissing and sexual relations. Onset of sexual relations was shorter for those who involved in sexual intimacy. Sexual intercourse happened without protection or communication and for women only after persuasion or without consent. Among unmarried youth, many them had expected to marry their romantic partner, but for one third of girls and a half of boys, the relationship had been discontinued. Analyzing the data set in a multivariate framework, Alexander et al (2007) found that among boys, 17-24\% had a romantic relationship and 20-26\% had engaged in some form of physical intimacy. Also, and 16-18\% of boys had completed sexual intercourse. The proportions among girls on the same parameters were found to be 5-8\%, 4$6 \%$ and 1-2\%, respectively. Usage of alcohol, watching pornographic films, frequent interaction with peer group and usage of drugs were positively associated with romantic and sexual relationships for both genders. Educational qualification was negatively associated with both types of relationships for girls, but only with sexual relationships for boys. Closeness to parents had a negative relationship with such relationships. For girls, whose father beat their mother were more likely than other young women to form romantic partnerships, and those youths who were beaten by their family were vulnerable to romantic and sexual partnerships. Strict parental supervision was not related to formation of such relationship significantly. In light of the above results, the authors highlighted sexuality education programs in schools and community for young men and women to address relationship issues and reproductive health and safety. The authors emphasized the need to sensitize parents on discussing sexual matters with children and to provide an equitable socialization patterns for boys and girls at home.

A more representative and a comprehensive study on youth involving young adults from five states in India namely, Andhra Pradesh, Bihar, Jharkhand, Maharashtra, Rajasthan and Tamil Nadu was conducted by International Institute of Population Sciences (IIPS; Youth in India: Situation and Needs,2010). The study was conducted, to understand the experiences of young people in terms of education milestones, work force participation, sexual activity, marriage, and civic participation. The results with regard to premarital sexual and romantic experiences revealed that $23 \%$ of boys and $21 \%$ of girls had experienced premarital sex by either initiating or accepting a romantic proposal. The study found that though youth report relatively traditional attitudes, opportunities to form romantic relationships did exist for some of them, irrespective of rural-urban residence or sex.

In a study using mixed method design, Gala \& Kapadia, interviewed 30 young adults to understand their experienced realties in the context of romantic relationships and its consequent developmental outcomes. The analysis of data revealed that, emerging adults found these relationships more satisfying than dissatisfying. It was also found that romantic relationships have significant and lasting impact on an individual's development. Participants from both the gender reported a positive change in the quality of life, which included positive feelings of happiness and reducing negative states such as anger and sadness. The authors were in favour of the need for enhancing positive developmental outcomes.

Using a quantitative survey design Ganth \& Kadhiravan (2013), conducted a study among University students to examine the psychosocial determinants of romantic inclination. They conceptualized that romantic inclination is "a degree of desire among unmarried youth toward developing a romantic relationship". It involves positive and favourable attitudes toward developing romantic relationship. The study involved 779 students from a large central university in the age range of 18-24 years participating and filling questionnaires on personality, attachment style, interpersonal attraction and social influence on romantic relationship. Those who had experienced a romantic relationship showed higher romantic inclination than those who had not. In a regression model, extraversion, openness to experience, agreeableness, media influence, peer influence, secure attachment and physical attachment emerged as significant predictors of romantic inclination. Structural equations Modelling indicated that personality, attachment style and interpersonal attraction had a significant influence on romantic inclination strongly mediated by both media and peer influences. Romantic inclination in turn significantly predicted love status.

The authors opined that parents, counsellors, educators and policy makers and youth themselves need to be educated on the normative and developmental aspects of youthful romance and they suggested relationship training programmes for youth both at the community and institutional levels.

Another qualitative with a narrative focus examined the partner selection strategies among young Indians (Netting, 2010). The sample included 15 male and 15 female, well-educated, upper middle class young adults. The results showed that "educated youth have moved beyond the conventional love-versus-arranged marriage dichotomy. They instead focus on achieving specific goals: intimacy, equality, and personal choice, along with supernatural support, growing into love, and brides joining husbands' families. To achieve these aims, they use both systems: separately, simultaneously, and in creative combinations". Although arranged marriage has survived in India, the current influx of new commodities, media, and ideas increasingly challenge the custom. As noted by Appadurai (2004), the "Western-inspired ideoscape of romantic love encounters Indian 
family values, Indian upper-middle-class youth respond by generating hybrid goals and systems of mate selection". The author was of the opinion that contemporary youth in India have "linked imagination to hope and are using voice within their families to win the recognition, and often the partners, they seek".

An examination of the above studies done among Indian youth indicates that prevalence of premarital romantic relationship with or without sexual contact is on the rise and the attitude of youth towards such relationships are fast changing. Individual level factors such as attitude and knowledge on premarital sex, exposure to alcohol, watching pornographic films and self-efficacy were related to premarital relationship. Opportunities to interact with peer group, peer pressure, family environment, strict parental supervision and educational attainment also do play a role in development of such relationship. More men reported to have such relationship than women, though, the possibility of underreporting from both genders couldn't be ruled out.

\section{Cross-cultural studies}

In the recent past, there is a growing interest among the relationship research scholars to look at romantic relationship through the lenses of culture and social context in which it happens. A few studies have included youth from India as a reference group representing traditional culture and have compared them against more liberal and westernized group.

In a cross-cultural study involving Indian and Canadian youth, Dhariwal \& Connolly (2013) examined 1316 Indian youth from three intra-ethnic group differing in levels of exposure to westernization: students from "traditional" Indian homeland single-sex schools, "transitional" Indian homeland co-educational schools, and the immigrant "diaspora" in Canadian schools. Results showed youth in the three contexts were similar on romantic desire but not on romantic autonomy and involvement. Increasing levels of westernization among youth favoured more romantic activities and greater perceived autonomy from parents in partner choice. Youth in a more westernized context were more likely to consume Western and social media, and possess friends fostering permissive expectations, greater cross-sex network composition, and intimate communication. The results suggested that involvement with the global media and friends explained the link between the cultural spectrum and romantic experiences. The authors suggested that youth in globalizing context need to be supported with the social networks particularly if their access to traditional kinship resources is diminished. Based on the results of the study, the authors suggested that parents can be helped to understand the ways in which their children are changed by the cultural setting via media and peers.

Neto (2007) conducted a cross-cultural study to compare attitudes toward love in three cultures: England, India, and Portugal. The author chose above cultures due to difference with respect to individualism and to the tradition of nuclear families based on romantic courtships. The main aim of the study was to test the gender and cultural differences as well as gender-culture interaction in love attitudes among youth in these three cultures. A total of 231 British (115 male and 116 female), 154 Indians (87 male and 67 female), and 177 Portuguese ( 86 male and 91 female) young adults participated in the study. The results revealed that men showed permissive, friendship oriented styles more than women did. Women showed more maniac styles than men. Eros(passionate) was comparable across cultures. Gender differences were shown in many styles across cultures. Culture and gender interaction was shown in most of the styles in all cultures. The author opined that any discussion of culture in love styles must embrace both gender and cultural differences and similarities.

Medora, Larson, Hortaçsu, Paruldave (2002) examined the cross-cultural differences in romanticism and desired qualities in a prospective partner among young adults from America, Turkey, and India. The total sample consisted of 200 American youth, 223 Turkish college students in and 218 Indian young adults. The results showed that the American young adults were most romantic, followed by the Turkish students, and Indians had the lowest romanticism score. Cultural differences were found in the desired qualities in a prospective partner. Participants differed significantly in their partner preferences which include having similar political ideologies, being well educated, being affectionate, having a good job, having similar interests, and not having a prior marriage. The authors viewed that western concept of romantic love does not fit well within the cultural context of India and they concluded that satisfaction in Indian marriages is more closely linked and tied to a respect for tradition and commitment to cultural heritage instead of feelings of closeness and intimacy between the marital partners.

\section{Issues in youthful romance: Recommendations for practice}

The studies discussed above paint a clear picture of the need for sensitization and education of the stakeholders of youth on the probable issues and complications involving romantic/sexual relationship among youth. A few recommendations for all concerned are presented below.

\section{For Parents, Teachers, and Institutions}

1. There is a need for parents and teachers to understand that development of romantic relationship among youth is a natural and developmental phenomenon. Instead of showing extreme negative reactions to any 
such romantic activities of youth, they may show openness and empathy in understanding the developmental trajectories involved.

2. Parents need to understand that their ward has equal right, as parents themselves have, on the selection of their own life partner. When the parents realize the romantic activities of the youth, they might not indulge in showing resentment and anger and resort to hastily arranging marriage for the ward. An open discussion on the need for informed decisions in a long term bonding such as marriage, would help resolve the family conflict in this regard.

3. As recommended by many aforesaid studies, teachers and parents should be sensitized about the increase in prevalence of romantic relationship among youth and they need to be trained on how to handle the issue without damaging the rights of the youth.

4. Handling the issues of romantic and sexual relationship might be embedded into the school/college mental health programmes in light of the increased instances of suicides, relationship aggression and violence among Indian youth involving romantic/sexual relationship.

\section{For Youth/Students}

1. The youth might realize that interest in the opposite gender and development of romantic relationship is common among youth but not to overshadow other developmental milestones like academic fulfillment, career orientation etc. They need to realize that while such relationship can give an elated feeling, and fulfill one's social and esteem needs, it could also be a distracter from the goals of life and potential threat success in one's academic and career, if pursued frantically.

2. As many decisions in romantic relationship, especially during adolescence and late adolescence are taken in a passionate, hasty, and fantasized state of mind, the decisions pertaining to partner choice, compatibility and suitability could be influenced by positive illusions. Thus, a hasty and compulsive indulgence of romantic relationship which is influenced to a great extent by media and peer group could lead to many social and psychological complications. The wrong choice or decision in romantic relationship could be detrimental to one's marital life.

3. Realizing the above, the youth should minimize fantasy orientation but resort to realistic thinking. Selecting the right partner at the right time could be the key for a happy married life.

\section{Acknowledgement}

The authors are grateful to the University Grants Commission, Government of India for partially funding the study involved in writing this paper.

\section{References}

[1]. Abraham, L. (2002). Bhai-behen, true love, time pass: Friendships and sexual partnerships among youth in an Indian metropolis. Culture, Health \& Sexuality, 4(3), 337-353.

[2]. Abraham, L., \& Kumar, A.K. (1999). Sexual experiences and their correlates among college students in Mumbai City, India. International Family Planning Perspectives, 25(3): p. 139-152.

[3]. Alexander, M., Garda, L., Kanade, S., Jejeebhoy, S., \& Ganatra, B. (2006). Romance and sex: pre-marital partnership formation among young women and men, Pune district, India. Reproductive health matters, 14(28), 144-155.

[4]. Alexander, M., Garda, L., Kanade, S., Jejeebhoy, S., \& Ganatra, B. (2007). Correlates of premarital relationships among unmarried youth in Pune district, Maharashtra, India. International Family Planning Perspectives, 33(4): pp. 150-9.

[5]. Appadurai, A. (2004). The capacity to aspire. Rao, V., and M. Walton (eds.). Culture and public action (pp. 59-84). Stanford, CA: Stanford University Press.

[6]. Dhariwal, A., \& Connolly, J. (2013). Romantic experiences of homeland and diaspora South Asian youth:Westernizing processes of media and friends. Journal of Research on Adolescence, 23(1), 45-56.

[7]. Gala, J., \& Kapadia, S. (2013). Romantic relationships in emerging adulthood: A developmental perspective. Psychological Studies, 58(4), 406-418.

[8]. Ganth, D. B., \& Kadhiravan, S. (2013). Psychosocial Determinants of Romantic Inclination among Youth. Unpublished Doctoral Disseration. Periyar Universitry.

[9]. Gupta, G. R. (1976). Love, arranged marriage, and the Indian social structure. Journal of Comparative Family Studies, 75-85.

[10]. International Institute for Population Sciences (IIPS) and Population Council. 2010. Youth in India: Situation and Needs 2006-2007. Mumbai: IIPS.

[11]. Medora, N. P., Larson, J. H., Hortacsu, \& Dave, P. (2002). Perceived attitudes towards romanticism; a cross-cultural study of American, Asian-Indian, and Turkish young adults. Journal of Comparative Family Studies, 155-178. 
[12]. Netting, N. S. (2010). Marital ideoscapes in 21st-century India: Creative combinations of love and responsibility. Journal of Family Issues, 31(6), 707-726.

[13]. Neto, F. (2007). Love styles: A cross-cultural study of British, Indian, and Portuguese college students. Journal of comparative family studies, 239-254. 